directly reproduced figures or tables published by other authors. Book publishers, other than the AGU, stopped or greatly reduced the reproduction of material published by the AGU. Now figures are often redrawn, tables are often recalculated or recast, and the original author is, as a consequence, often not referenced. The AGU publications office has failed to recognize that an author's primary goal in writing an article is to be recognized and referenced. It is my experience that the authors are not concerned with how their work is used (or even misused). They want recognition (and another reference in the Citation Index ).

Ragan and Holoviak correctly perceive that the new copyright law 'could cripple the wide dissemination of scientific information.' They list some (but not all) of these crippling aspects. It is obvious that anything that cripples, or even hinders slightly, the dissemination of a scientific article will also cripple the growth of the reputation and influence of its author (and his Citation Index count). Authors of scientific articles do not derive their livelihood directly from these articles as do authors of novels or plays. Their livelihood as an author of an article in an AGU scientific journal is primarily influenced by the extent to which their work is read and referenced. The more their work is indexed, translated, abstracted, republished (totally or in part), or photocopied, the better it is for their reputations as scientists. Presumably, they will be suitably rewarded with promotions, raises in salary, invitations to speak, honoraria, etc.

Ragan and Holoviak recognize that 'roadblocks [to the efficient dissemination of scientific information] could be removed if all authors placed their work in the public domain.' However, they counsel against this course, and they present three principal arguments in support of their conclusion. I should like to examine briefly each of their arguments.

1. 'The principle of an author's rights over the intellectual property he produces' should be regarded. To repeat, the author of a journal article is primarily interested in being read, quoted, copied, and referenced. The more photocopying and reprinting, etc., the better.

2. 'The continuing slow erosion of subscription income' would become a more severe problem. I believe that Clive Lister in a Forum letter (February $1978 \mathrm{E} \oplus \mathrm{S}$, p. 66) represents the attitude of many in the AGU when he writes, 'I read your paean of complaint about publishing trends (July $1977 \mathrm{E} \oplus \mathrm{S})$ with limited sympathy.' It is quite likely that one or more of the several developing technologies will eventually produce an innovative replacement for the crush of journal paper we now receive. If such a change is to take place, let us welcome it; the new copyright law should not be used to block or even slow a superior evolutionary development. Protectionist attempts to stop progress will not work, but we will all be made uncomfortable while there is a struggle to maintain the status quo.

3. 'Finally, a strong primary publications program ... forms the foundation for the evolution ... that you will need in the future.' This statement refers, I presume, to financial stability for AGU journals coupled with experimentation with new methods of publication. I do not see that copyrighting has anything to do with either experiments or financial stability. The AGU got along just fine before 1969 without copyrights, and the post-1969 income from copyright activities has been virtually nil. In fact, I believe it is evident that AGU copyrighting practices thus far have not served to encourage the development of alternate publication methods (although neither do I believe that the development of new methods will, in the long run, be blocked by copyright practices).

I would like to make the following specific proposal. Let us try, as an experiment, reverting to our pre-1969 practice of not copyrighting AGU scientific articles, and let us place these articles in the public domain. If nothing bad happens, we will have simplified our lives as authors and served the cause of science. If something bad does seem to be occurring, we could do some controlled experiments by, say, copyrighting the articles in just one journal, or even one section of JGR, to see what difference copyrighting makes. In other words, I propose an experiment that holds the prospect of more benefit than risk.

\author{
A. J. Dessler \\ Department of Space Physics \\ and Astronomy \\ Rice University
}

\section{Scientific Drilling}

I was very pleased to read the support given to a new program of future scientific drilling on the President's Page of April $1978 \mathrm{E} \oplus \mathrm{S}$. There was, however, a matter which deeply concerned me and which was omitted in the discussion. Experience has shown that it is imperative to identify the science function as an intrinsic part of an enterprise such as this. Unless there is proper support for the scientific studies both on board ship and in the land laboratories, there will not be an adequate scientific return. It is very easy to place large efforts in the exploration and technical aspects without sufficient regard to the 'post mission' scientific work that must be done. This matter is particularly serious when the status of most research groups is severely limited by lack of funds for the construction and purchase of equipment and the lack of support for research and operating staff on a prolonged time basis. There is also some concern on my part for the long-time curation of the materials which are returned from deep-sea exploration. I am certain that Mr. Maxwell is sensitive to the importance of supporting and carrying out vigorous scientific researches as an inherent part of a new generation JOIDES project. My personal enthusiasm for this enterprise is only limited by the extent to which these matters are given a proper part in the intrinsic definition of the project.

$$
\begin{aligned}
& \text { G. J. Wasserburg } \\
& \text { Professor of Geology } \\
& \text { and Geophysics } \\
& \text { California Institute } \\
& \text { of Technology }
\end{aligned}
$$

